NBER WORKING PAPER SERIES

ESTIMATED MACROECONOMIC

EFFECTS OF DEFICIT TARGETING

\author{
Ray C. Fair
}

Working Paper No. 1814

NATIONAL BUREAU OF ECONOMIC RESEARCH

1050 Massachusetts Avenue

Cambridge, MA 02138

January 1986

The research reported here is part of the NBER's research program in Economic Fluctuations and project in Government Budgets. Any opinions expressed are those of the author and not those of the National Bureau of Economic Research. 
NBER Working Paper \#1814 January 1986

Estimated Macroeconomic Effects of Deficit Targeting

\section{ABSTRACT}

Some macroeconomic effects of deficit targeting are estimated in this paper using my U.S. econometric mode1. The response of the economy to rea1 and price shocks is examined in a number of cases. Each case corresponds to a particular assumption about fiscal policy and a particular assumption about monetary policy. Estimates are also presented of the size of the government spending cuts that are needed to meet a given deficit goal under different assumptions about monetary policy.

Ray C. Fair

Cowles Foundation for Research in Economics Department of. Economics Box 2125 Yale Station Yale University

New Haven, CT 06520 
January 1986

\title{
ESTIMATED MACROECONOMIC EFFECTS OF DEFICIT TARGETING
}

\author{
by \\ Ray C. Fair
}

\section{Introduction}

Given the passage of the Gramm-Rudman bill, it is of interest to examine the macroeconomic consequences of deficit targeting. The bill sets a target for the deficit each year, which as a last resort is to be met by automatic spending cuts under the direction of the office of Management and Budget and the Congressional Budget office. The bill has the effect of making fiscal policy endogenous. The deficit is set to a fixed target value each year and is thus exogenous. Fiscal policy must be set so as to achieve the target, and so it is endogenous. As a last resort, government spending is the variable that allows the target to be achieved.

Some macroeconomic effects of deficit targeting are estimated in this paper using my econometric model of the United States. The response of the economy to real and price shocks is examined in a number of cases. Each case corresponds to a particular assumption about fiscal policy and a particular assumption about monetary policy. The model and the experiments are explained in section II, and the results of the experiments are presented and discussed in Section III. In Section IV estimates are presented of the size of the expenditure cuts that are needed to meet a given deficit goal under different assumptions about monetary policy. Concluding and qualifying remarks are presented in section $V$.

The main results of the paper are fairly easy to summarize. A negative demand shock, such as a decrease in exports, contracts the economy. Taxable 
income in less, and so government tax receipts fall, which increases the deficit. If the deficit is prevented from changing, government spending must fall or tax rates must rise, which is a contractionary fiscal-policy action. Therefore, when the deficit is exogenous, the negative response of the economy to, say, a decrease in exports is larger because of the combination of the drop in exports and the contraction in fiscal policy. The size of the response differences depends on what is assumed about monetary policy and which fiscal-policy variable is taken to be endogenous (i.e., which variable adjusts to keep the deficit unchanged). For the particular experiments in this paper, the decrease in real GNP four quarters after the demand shock is between 7 and 59 percent greater in the exogenous deficit case. The decrease eight quarters after the shock is between 26 and 65 percent greater.

The response differences to a price shock are much smaller. A positive price shock, such as an increase in the price of imports, is inflationary and contractionary. The contraction lowers tax receipts, but the inflation raises them, and the net effect on the deficit is small. Since the deficit is little affected by price shocks, whether or not it is forced to remain unchanged after a price shock is of little consequence.

Consider now no shocks, but assume that the deficit needs to be lowered to meet the target for the year. If this is to be done by a fall in government spending, what size cuts are needed to meet a given goal? The answer to this question obviously depends on what is assumed about monetary policy. For the experiments in this paper, a lowering of the deficit by 20 billion dollars required a cut in government spending of 31.2 billion dollars in the first year under the assumption that the Federal Reserve 
targets the money supply. This lowered nominal GNP by 43.7 billion dollars and rea1 GNP by 18.7 billion (1972) dollars. Spending has to be cut more than the required cut in the deficit because of the decreased tax revenue that results from the contractionary economy.

The last set of estimates in this paper concerns the size of the monetary policy expansion that would be needed to keep real or nominal GNP unchanged after a government spending cut. For the experiments here a lowering of the deficit by 20 billion dollars required a fall in the threemonth Treasury bill rate of 2.0 percentage points to keep real GNP roughly unchanged. This resulted in an increase in the money supply of 7.1 billion dollars four quarters after the initial change.

\section{The Mode 1 and the Experiments}

The model is described in detail in Fair (1984), and it will only be briefly explained here. The model is particularly suited to examining the effects of deficit targeting because it accounts for all the flows of funds among the sectors and all the balance-sheet constraints. The value of each sector's financial savings (or dissavings) is determined by an identity in the model. The value of a sector's savings is equal to its income minus its expenditures. The sum of the savings across all sectors is zero, since someone's expenditure is someone else's income. If, for example, the government is running a deficit, at least one other sector in the model must be running a surplus. Also, any nonzero value of a sector's savings must result in the change in at least one of its financial assets or liabilities.

There are six sectors in the model: household, firm, financial, foreign, state and local government, and federal government. The surplus or 
deficit of the federal government is determined by the savings identity for the sector. The "government budget constraint" is the equation that relates the level of savings of the government to changes in its assets and liabilities. ("Government" henceforth will always refer to the federal government.)

\section{Fiscal Policy Assumptions}

It will be useful at this point to consider the alternative fiscal policy assumptions that were used in this paper. In the regular version of the model real government purchases of goods, government employment, government transfer payments, and various tax rates are exogenous. The deficit is endogenous. This will be called case (1). When the deficit is taken to be exogenous, many cases are possible, depending on which government policy variable is taken to be endogenous. Three possibilities are considered in this paper: case (2), real purchases of goods endogenous; case (3), transfer payments endogenous; and case (4), the personal tax rate endogenous. 1

\section{Monetary Policy Assumptions}

The accounting for flow-of-fund and balance-sheet constraints makes the treatment of alternative monetary policy assumptions straightforward. The main monetary policy instrument is the amount of government securities outstanding, which is the open-market-operations variable. (The other two instruments are the discount rate and the reserve requirement ratio.) By manipulation of this variable the Federal Reserve (henceforth the "Fed") can

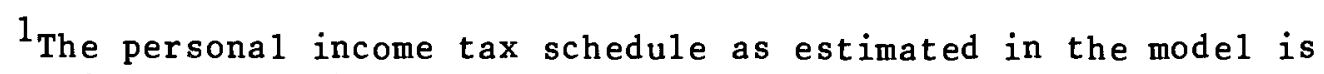
progressive, and so both the average and marginal personal income tax rates are endogenous. There is, however, an exogenous tax parameter associated with the tax schedule, and this is the parameter that has been made endogenous in case (4). 
target interest rates or monetary aggregates. Many assumptions about monetary policy are possible in the model. The assumption that I use most is that the Fed behaves according to an estimated "interest rate reaction function." According to this equation, the Fed "leans against the wind." The Fed is estimated to let the short term interest rate rise in response to increases in real output growth, labor market tightness, inflation, and the lagged growth of the money supply. (The short term interest rate in the model is the three-month Treasury bill rate. In what follows, "interest rate" will refer to the Treasury bill rate unless indicated otherwise.) When this assumption is used, monetary policy is endogenous: the interest rate reaction function is one of the stochastic equations of the model. The open-market-operations variable is endogenous. Its solution value is whatever is needed to have the interest rate as computed by the interest rate reaction function be met. The use of the interest rate reaction function will be called case (a).

Another possible monetary policy assumption is that the Fed targets the money supply (M1) and the target is fixed. This assumption will be called case (b). In this case the interest rate reaction function is dropped from the mode1. The open-market-operations variable is still endogenous, but in this case its solution value is whatever is needed to have the M1 target be met. Monetary policy is not endogenous in this case because there is no M1 reaction function. $M 1$ is simply treated as the exogenous policy variable of the Fed.

A third possible assumption is that the Fed targets the interest rate and the target is fixed. This assumption will be called case (c). This case is like case (a) except that there is no equation determining the 
interest rate. The interest rate is instead treated as the exogenous policy variable of the Fed.

A fourth possible assumption is that the Fed targets nonborrowed reserves. A fifth is that it targets the open-market-operations variable itself, i.e., the amount of government securities outstanding, although in general this is not likely to be a realistic description of Fed behavior. A sixth possibility is that the Fed targets real GNP, and a seventh is that it targets nominal GNP. The fourth and fifth assumptions are not considered in this paper. The sixth and seventh assumptions will be considered in Section IV. They will be called cases (d) and (e) respectively. Stochastic Equations

The main stochastic equations for the household sector determine consumption, housing investment, labor supply, and the household sector's demand for money. The main stochastic equations for the firm sector determine prices, wages, production, plant and equipment investment, employment, and the firm sector's demand for money. The financial sector contains two term structure of interest rate equations, a stock price equation, an equation determining the demand for currency, and an equation determining bank borrowing from the Fed. The foreign sector contains a demand for imports equation, and the state and local government sector contains an equation determining unemployment insurance benefits. The federal government sector contains an interest payments equation and, when appropriate, the interest rate reaction function. The equations have been estimated by two stage least squares. The estimation period for the work here is 1954 I - 1985 III, for a total of 127 quarterly observations. The theory that has guided the specification of the stochastic 
equations is that households maximize utility and firms maximize profits. The variables that explain consumption and labor supply are variables that one would expect from the microeconomic analysis of a household's multiperiod utility maximizing problem: the after-tax real wage, after-tax nonlabor income, wealth, and interest rates.

The model of firm behavior is somewhat more involved. The theory will not be discussed in detail here. The main estimated equations have the following features. Prices and wages affect each other and are affected by demand conditions. In addition, the price of imports has an important effect on domestic prices. Firms are estimated to raise the prices of their goods in response to an increase in import prices. This result can be justified on standard oligopolistic pricing grounds, and the theoretical model upon which the econometric specifications are based is one in which firms have a certain amount of oligopolistic pricing power in the short run.

Production is determined by sales and the initial stock of inventories. (The level of sales is determined by an identity.) Plant and equipment investment is determined by current and past values of production and by the amount of excess capital on hand. Employment is also determined by current and past values of production and by the amount of excess labor on hand. Interest rates do not appear in the investment equation. I have been unable in my work to find direct interest rate effects on plant and equipment investment. Interest rates do, however, have important direct effects on housing investment in the model. In addition, interest rates have important indirect effects on plant and equipment investment, which will be discussed short1y

The theoretical model allows for the possibility of "disequilibrium." 
Agents in the model do not have rational expectations. In particular, firms may set prices and wages wrong because of expectation errors. If decisions are made that result in excess supply in the labor market, then households are constrained in how much they can work. They are forced (as a group) to work less than they would like to at the current set of wages and prices. This constraint also leads them to consume less. In the econometric work I have tried to approximate this possible disequilibrium effect by constructing a "labor constraint" variable that is zero or close to zero when labor markets are tight and that gets further and further from zero as labor markets become looser and looser. This variable is an explanatory variable in the consumption and labor supply equations, and it is in general quite significant. The results rather strongly indicate that disequilibrium effects are at times important.

\section{Some Properties of the Mode1}

It will be helpful in understanding the results in the next two sections to review a few of the model's properties.

1. An increase in interest rates decreases consumption and housing investment, which means a decrease in sales of the firm sector. The decrease in sales leads to a cut in production, which in turn leads to falls in plant and equipment investment and employment. Interest rates thus have an indirect negative effect on plant and equipment investment.

2. An increase in the personal income tax rate lowers the after-tax real wage, which in turn lowers consumption, housing investment, and labor supply.

3. A decrease in transfer payments lowers nonlabor income, which lowers consumption and housing investment and raises labor supply.

4. The response of the economy to a decrease in government purchases of goods is faster than it is for a decrease in transfer payments or an increase in the personal income tax rate. The decrease in government purchases directly affects sales of the firm sector, whereas a decrease in transfer payments or an increase in the tax rate must work through the expenditure decisions of the household sector first before sales 
are affected.

5. The demand for money of the household sector is a function of income and the interest rate. Similarly, the demand for money of the firm sector is a function of the level of sales and the interest rate.

6. An increase in the price of imports is both inflationary and contractionary. It is inflationary because it works directly through the price equation for the firm sector. It is contractionary because it initially leads to a fall in the real wage (nominal wages do not respond as fast to an import price change as do prices), which lowers consumption and housing investment, which lowers sales, and so on. Another possible source of contraction is the Fed. If the interest rate reaction function is in the model, an increase in prices will lead the Fed to raise short term interest rates, which will lower consumption and housing investment, and so on.

7. In periods of disequilibrium, where the labor constraint variable is not close to zero, multiplier reactions can be generated in the model. Consider some event that lowers the sales of the firm sector. This lowers production, which in turn lowers investment and employment. Lower employment implies a decrease in labor market tightness, which implies an increase in the labor constraint variable, which in turn leads to lower consumption. Lower consumption implies lower sales of the firm sector, which lowers production even further, and so on.

\section{The Experiments}

The experiments were performed as follows. The period considered was 1981 I - 1985 III, for a total of 19 quarters. The estimated residuals were first added to the stochastic equations for this period and treated as exogenous. This means that when the model is solved for this period using the actual values of the exogenous variables, the predicted values of the endogenous variables are simply the actual values. In other words, a perfect tracking solution is obtained. The perfect tracking solution will be called the "base path." The first set of experiments corresponded to changing the real value of exports (a real shock), and the second set corresponded to changing the price of imports (a price shock). The real value of exports was changed each quarter (from the value in the base path) to correspond roughly to a 4 billion dollar decrease in nominal exports (at 
an annual rate).2 (Al1 flows in this paper are at annual rates.) The model was then solved for these changes. The differences between the new solution values and the old solution values (i.e., the actual values) are the estimated effects of the change. For the second set of experiments, the price of imports was increased by 10 percent each quarter from the value in the base path.

III. The Results

Effects of Alternative Monetary Policy Assumptions -- Table 1

Given the large number of potential cases, it will be useful to consider a few at a time. The results in Table 1 show the sensitivity of the effects of the export decrease to three monetary policy assumptions: (a) the interest rate reaction function used, (b) the money supply exogenous, and (c) the interest rate exogenous.

The interest rate falls slightly more when the interest rate reaction function is used than when the money supply is taken to be exogenous, and so case (a) is less contractionary than case (b). The most contractionary case is (c), where the interest rate is exogenous. In this case the interest rate is not allowed to fall at all in response to the drop in demand. The money supply falls in case (c) because, with the interest rate constant, the fall in income and sales as a result of the fall in exports leads to a decrease in the demand for money. The reason the interest rate falls in case (b) is to offset what would otherwise be a decrease in the demand for

2 I say "roughly" here because the nominal value of exports is an endogenous variable because the price of exports is endogenous. The change in the real value of exports was made to correspond to a 10 billion dollar decrease in nominal exports had the price of exports remained unchanged from the base case. 
TABLE 1. Estimated Effects of a Sustained Decrease in Exports

Fiscal Policy (1): Government deficit is endogenous

\begin{tabular}{|c|c|c|c|c|c|c|c|c|c|c|c|}
\hline \multicolumn{3}{|c|}{ Monetary } & \multicolumn{2}{|c|}{ Quarte } & ahead & \multicolumn{2}{|c|}{ (Beginning } & \multicolumn{3}{|c|}{ quarter $1981 \mathrm{I}$ ) } & \multirow[b]{2}{*}{16} \\
\hline Variable & Policy & 1 & 2 & 3 & 4 & 5 & 6 & 7 & 8 & 12 & \\
\hline & & & $n t$ & & & & & & & & \\
\hline & (a) & -.08 & -.12 & -.14 & -.16 & -.17 & -.17 & -.17 & -.18 & -.16 & -.16 \\
\hline & $\begin{array}{l}\text { (b) } \\
\text { (c) }\end{array}$ & $\begin{array}{r}-.02 \\
0\end{array}$ & $\begin{array}{r}-.05 \\
0\end{array}$ & $\begin{array}{r}-.08 \\
0\end{array}$ & $\begin{array}{r}-.09 \\
0\end{array}$ & -.10 & -.11 & -.11 & -.11 & $\begin{array}{r}-.12 \\
0\end{array}$ & -.11 \\
\hline
\end{tabular}

Money Supply (B\$)

$\begin{array}{lrrrrrrrrrr}\text { (a) } & .1 & .1 & .2 & .3 & .3 & .4 & .5 & .5 & .8 & .9 \\ \text { (b) } & 0 & 0 & 0 & 0 & 0 & 0 & 0 & 0 & 0 & 0 \\ \text { (c) } & -.0 & -.1 & -.2 & -.3 & -.4 & -.5 & -.6 & -.8 & -1.3 & -1.8\end{array}$

Nominal GNP (B\$)

$\begin{array}{lllllllllllll}\text { (a) } & -7.1 & -11.2 & -13.9 & -15.6 & -16.3 & -16.8 & -16.7 & -16.9 & -16.8 & -17.5 \\ \text { (b) } & -7.2 & -11.5 & -14.5 & -16.7 & -17.7 & -18.6 & -18.8 & -19.3 & -20.0 & -21.1 \\ \text { (c) } & -7.2 & -11.6 & -14.9 & -17.4 & -18.9 & -20.4 & -21.2 & -22.2 & -25.1 & -27.7\end{array}$

Real GNP (B72\$)

$\begin{array}{lllllllllll}\text { (a) } & -4.5 & -6.1 & -6.8 & -6.9 & -6.7 & -6.4 & -6.0 & -5.7 & -4.3 & -3.9 \\ \text { (b) } & -4.6 & -6.3 & -7.1 & -7.4 & -7.3 & -7.2 & -6.9 & -6.6 & -5.3 & -4.8 \\ \text { (c) } & -4.6 & -6.3 & -7.3 & -7.8 & -7.9 & -7.9 & -7.9 & -7.8 & -7.1 & -6.7\end{array}$

GNP Deflator (percentage points)

$\begin{array}{lllllllllll}\text { (a) } & .05 & .02 & -.02 & -.06 & -.09 & -.12 & -.13 & -.16 & -.21 & -.23 \\ \text { (b) } & .05 & .02 & -.02 & -.06 & -.09 & -.13 & -.15 & -.18 & -.25 & -.27 \\ \text { (c) } & .05 & .02 & -.02 & -.06 & -.09 & -.13 & -.15 & -.19 & -.28 & -.33\end{array}$

Gov. Deficit (B\$)

$\begin{array}{lllllllllll}\text { (a) } & 2.0 & 3.1 & 3.8 & 4.0 & 4.1 & 4.1 & 3.8 & 3.6 & 3.0 & 2.9 \\ \text { (b) } & 2.1 & 3.2 & 4.1 & 4.4 & 4.6 & 4.7 & 4.6 & 4.4 & 4.3 & 4.4 \\ \text { (c) } & 2.1 & 3.3 & 4.2 & 4.7 & 5.1 & 5.4 & 5.4 & 5.5 & 6.4 & 7.2\end{array}$

Notes: 1. Monetary policy assumptions: (a) = interest rate reaction function. (b) = money supply is exogenous .

(c) = interest rate is exogenous.

2. $B \$=$ billions of current dollars, B72\$ = billions of 1972 dollars.

3. The real value of exports was changed each quarter to correspond roughly to a 10 billion dollar decrease in the value of nominal exports from the value in the base path. The numbers in the table are the changes in the variables (from the base-path values) induced by the export change. For all the variables except the GNP deflator, each number is new value - base value. For the GNP deflator,each number is 100 (new value - base value)/ hase value. 
money. The money supply rises slightly in case (a) because of the larger fall in the interest rate in this case than in case (b).

The fall in exports has led to an increase in the government deficit. For obvious reasons the deficit increases least in the least contractionary case and most in the most contractionary case. The increase is around 1 billion dollars after four quarters, which is around 25 percent of the shock.

It should be noted from Table 1 that cases a) and b) are closer to each other than are cases b) and c). In general, cases a) and b) are not too far apart, which means that the behavior that is reflected in the interest rate reaction function is not too different from the behavior of keeping the money supply unchanged from what it would otherwise be in response to a demand shock.

Effects of Alternative Fiseal Poticy Assumptions-- Table 2

Consider now the results in Table 2. The left half of the table is for the interest rate reaction function case, and the right half is for the exogenous money supply case. The exogenous interest rate case is not presented to conserve on space and because it seemed the least likely monetary policy response to the export shock. Four fiscal policy assumptions are considered for each of the two monetary policy assumptions. These have been discussed in Section II. Case (1) is the regular case of an endogenous deficit. In cases (2), (3), and (4) the deficit is exogenous, and a particular fiscal policy variable is taken to be endogenous.

The results in Table 2 show, as one would expect, that the output responses are larger when the deficit is exogenous. In the endogenous deficit case, the deficit rises in response to the export decrease, and so 


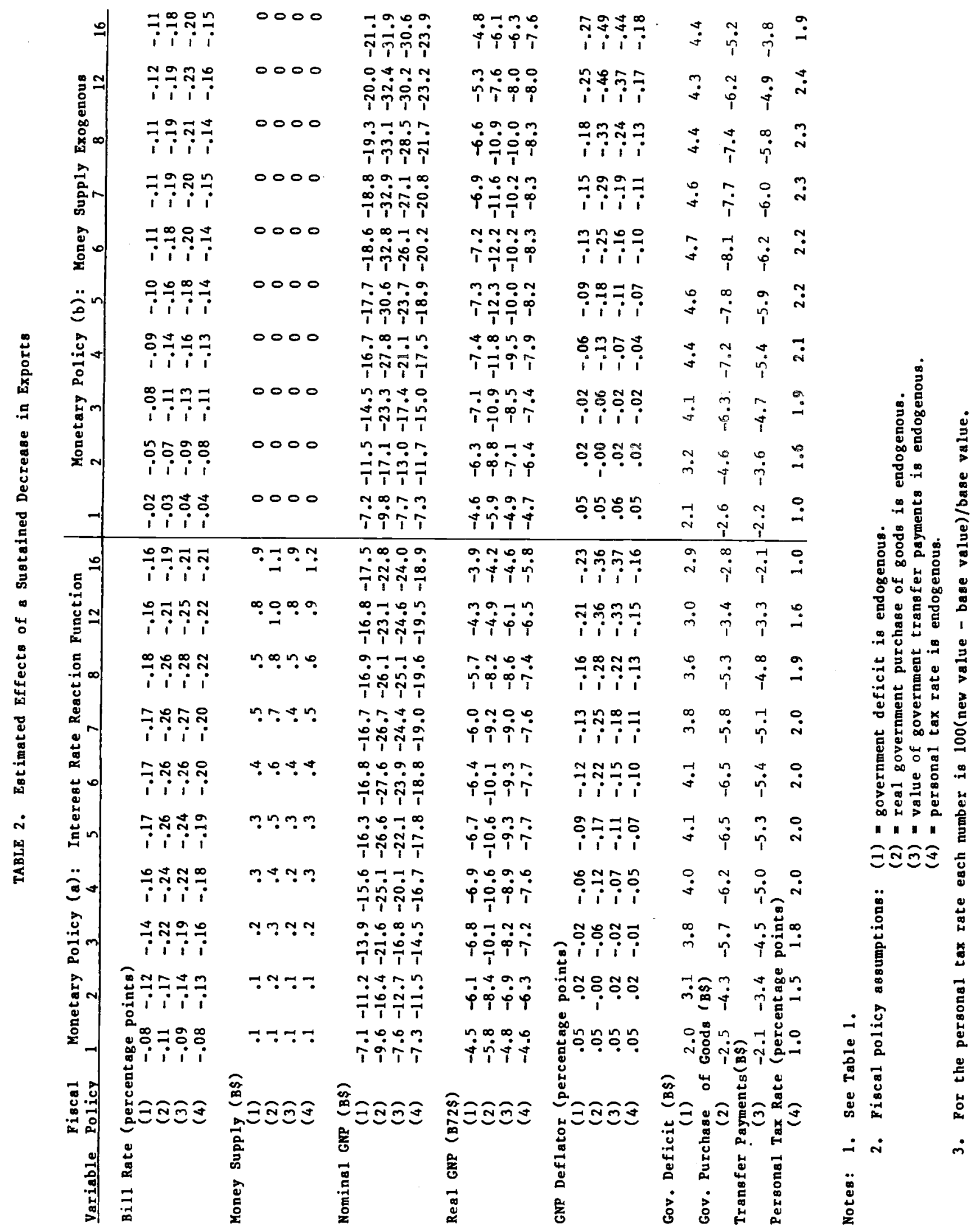


when it is exogenous and thus prevented from rising, government spending must fall or tax rates must rise. The export decrease is thus accompanied by a contractionary fiscal policy, and so the net effect is a larger decrease in output.

When the interest rate reaction function is used (case (a)), the decrease in real GNP after four quarters is 6.9 billion in the endogenous deficit case and is between 7.7 and 10.6 billion in the exogenous deficit cases. When the money supply is exogenous (case (b)), the corresponding numbers are 7.4 billion and between 7.9 and 11.8 billion. 7.9 is 7 percent greater than 7.4 , and 11.8 is 59 percent greater than 7.4 . The response differences thus range from 7 to 59 percent for the four-quarter-ahead results, which is the range mentioned in the Introduction. For the eightquarter-ahead results the range is 30 to 51 percent for case (a) -- 7.4 versus 5.7 and 8.6 versus 5.7 -- and 26 to 65 percent for case (b) -- 8.3 versus 6.6 and 10.9 versus 6.6 . The overall range in the eight-quarterahead case is thus 26 to 65 percent, which is also mentioned in the Introduction.

The output decreases are in general slightly larger in the exogenous money supply case. The interest rate reaction function in general calls for slightly larger decreases in the interest rate than does the assumption of an unchanged money supply, and this is the reason for the slightly less contractionary situation when the interest rate reaction function is used.

It was noted in Section II that output responses are faster for a change in government purchases of goods than they are for a change in transfer payments or tax rates. This is reflected in the results in Table 2. The output decreases in case (2) are initially larger than they are in 
cases (3) and (4). After sixteen quarters, however, the output decreases for cases (3) and (4) are slightly larger than those for case (2).

The last three rows in Table 2 show the amounts by which the endogenous fiscal policy variables were changed. After four quarters under monetary policy (a), government purchases of goods fell by 1.6 billion dollars, transfer payments fell by 1.2 billion dollars, and the personal tax rate increased by 2.0 percent. In each case the particular change offset what would otherwise have been a 1.0 billion dollar increase in the deficit.

Finally, the GNP deflator fell from the third quarter on as a result of the contraction. The small increases in the first two quarters are due to a change in weights for the GNP deflator that resulted from the export decrease. This is simply an artifact of the way the GNP deflator is defined. The GNP deflator dropped least in case (4), and this requires some explanation. When the personal tax rate rises, which means a fall in the after-tax real wage, labor supply falls. A falling labor supply implies a lower unemployment than otherwise, which in turn implies higher prices and wages than otherwise. There is thus a positive effect on prices and wages in the tax rate case that is missing in the other cases, and so the fall in prices and wages is less in the tax rate case.

\section{Effects of - a Price Shock -- Table 3}

The results for the increase in the price of imports are presented in just one table, Table 3 . The first three rows show the sensitivity of the results to the alternative monetary policy assumptions. The increase in the price of imports leads to an increase in the GNP deflator and a decrease in real GNP for reasons that were discussed in Section II. (Nominal GNP increases in Table 3, which is because of the increase in prices.) The 
TABLES 3. Estimated Effects of a Sustained Increase in the Price of Imports

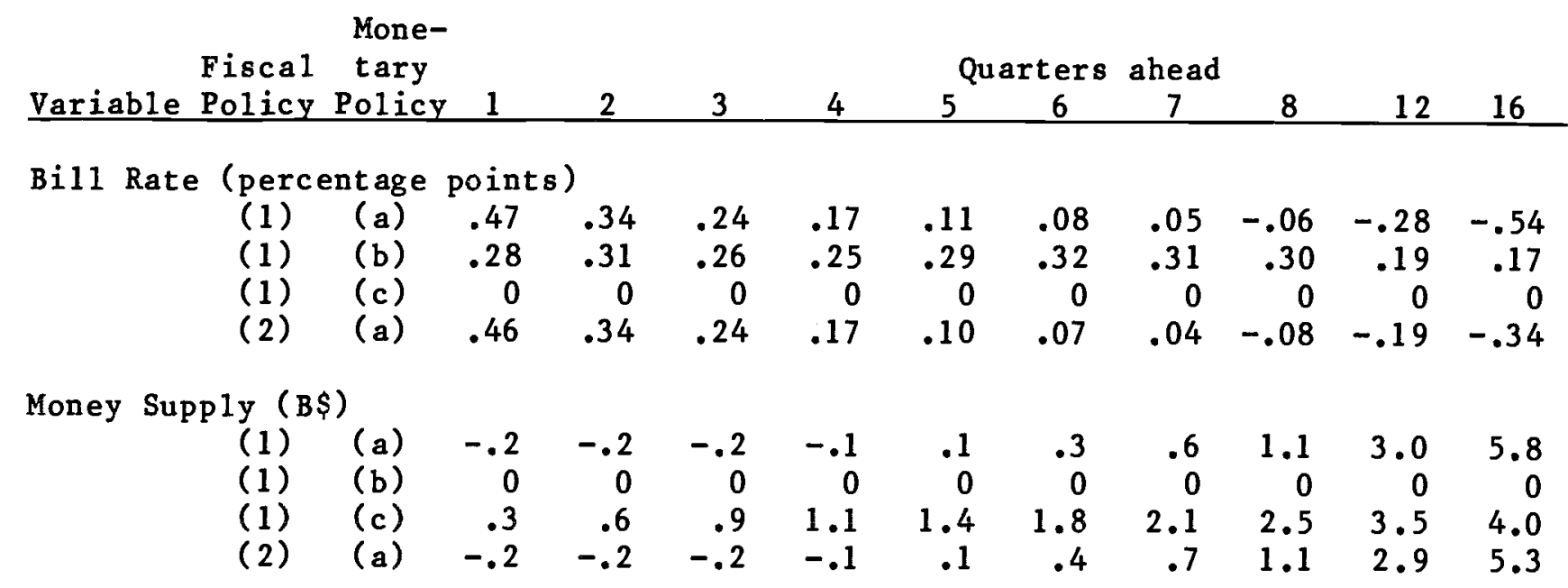

Nominal GNP (B\$)

$\begin{array}{llllllllllll}\text { (1) } & \text { (a) } & 7.3 & 10.4 & 13.2 & 15.2 & 17.2 & 20.0 & 23.1 & 25.1 & 46.3 & 68.0\end{array}$

$\begin{array}{llllllllllll}\text { (1) (b) } & 7.6 & 11.1 & 14.3 & 16.2 & 17.9 & 19.7 & 21.4 & 21.7 & 23.2 & 44.5\end{array}$

$\begin{array}{llllllllllll}\text { (1) } & \text { (c) } & 8.0 & 12.6 & 17.2 & 20.7 & 23.8 & 27.4 & 30.7 & 32.5 & 48.7 & 59.3\end{array}$

$\begin{array}{llllllllllll}\text { (2) } & \text { (a) } & 6.8 & 9.8 & 12.9 & 14.5 & 16.3 & 19.1 & 21.8 & 22.8 & 55.5 & 89.6\end{array}$

Real GNP (B72\$)

$\begin{array}{lllllllllllll}\text { (1) } & \text { (a) } & -2.8 & -4.9 & -7.4 & -9.9 & -12.4 & -14.9 & -17.4 & -19.7 & -27.5 & -33.1 \\ \text { (1) } & \text { (b) } & -2.7 & -4.5 & -6.9 & -9.5 & -12.3 & -15.2 & -18.3 & -21.4 & -32.3 & -41.0 \\ \text { (1) } & \text { (c) } & -2.4 & -3.7 & -5.5 & -7.5 & -9.7 & -12.1 & -14.7 & -17.3 & -27.9 & -37.7 \\ \text { (2) } & \text { (a) } & -3.2 & -5.1 & -7.5 & -10.2 & -12.7 & -15.2 & -17.9 & -20.5 & -23.8 & -26.2\end{array}$

GNP Deflator (percentage points)

\begin{tabular}{|c|c|c|c|c|c|c|c|c|c|c|c|}
\hline $\begin{array}{l}(1) \\
(1) \\
(1) \\
(2)\end{array}$ & $\begin{array}{l}\text { (a) } \\
\text { (b) } \\
\text { (c) } \\
\text { (a) }\end{array}$ & $\begin{array}{l}.44 \\
.44 \\
.44 \\
.44\end{array}$ & $\begin{array}{l}.68 \\
.68 \\
.68 \\
.68\end{array}$ & $\begin{array}{l}.93 \\
.93 \\
.93 \\
.93\end{array}$ & $\begin{array}{l}1.17 \\
1.18 \\
1.19 \\
1.17\end{array}$ & $\begin{array}{l}1.42 \\
1.43 \\
1.45 \\
1.41\end{array}$ & $\begin{array}{l}1.6 \\
1.6 \\
1.7 \\
1.6\end{array}$ & & $\begin{array}{l}1.95 \\
1.96 \\
2.01 \\
1.94\end{array}$ & $\begin{array}{l}2.17 \\
2.18 \\
2.24 \\
2.15\end{array}$ & $\begin{array}{ll}3.15 & 3.88 \\
3.11 & 3.74 \\
3.25 & 3.93 \\
3.18 & 4.02\end{array}$ \\
\hline
\end{tabular}

Gov. Deficit (B\$)
(1)
(1)
(a) .5
$\begin{array}{rr}.2 & -.0 \\ -.1 & -.04\end{array}$
$\begin{array}{rr}-.7 & -1.6 \\ 0 & 0\end{array}$
$\begin{array}{rr}.4 & .4 \\ .1 & .4 \\ -1.6 & -1.9 \\ 0 & 0\end{array}$
.4
$\begin{array}{lllll}.7 & 1.3 & -5.1 & -10.2\end{array}$
(1)
$\begin{array}{llll}\text { (b) } & .3 & -.1 & -.4\end{array}$
(c)
1
0

$$
0
$$

(1)

Notes: 1. See Table 1 for the units of the variables.

2. Monetary policy assumptions:

(a) = interest rate reaction function.
(b) = money supply is exogenous.
(c) = interest rate is exogenous.

3. Fiscal policy assumptions: (1) = government deficit is endogenous.
(2) = real government purchase of goods is exogenous.

4. The price of imports was changed by 10 percent each quarter from the base-path value. 
shock is both inflationary and contractionary.

With respect to the three monetary policy assumptions, case (c) is the least contractionary. In the other two cases the interest rate rises rather than remaining unchanged, which worsens the contraction. The interest rate reaction function (case (a)) implies a larger initial increase in the interest rate than does case (b), but in the third quarter the increase begins to be smaller and in the eighth quarter the change becomes negative. According to the interest rate reaction function, the Fed responds positively to inflation and negatively to real output contractions in its setting of the interest rate. For the results in Table 3 the positive inflation effect initially dominated, but after seven quarters the negative effect from the output contraction began to dominate. In case (b) the interest rate changes were always positive. The interest rate needed to rise to choke off what would otherwise be an increase in the demand for money as a result of the inflation.

The main result in Table 3 is that the effects on the deficit are smal1. The contraction lowers tax revenue, but the inflation raises it, and the net effect on the deficit is smal1. The change in the deficit after eight quarters merely ranged from -.3 to .7 billion dollars. This means that the results are not going to be sensitive to the treatment of the deficit as exogenous. This is shown in the fourth row of Table 3 , which is fiscal policy (2) and monetary policy (a). The differences between the first and fourth rows of the table are small, which is as expected given the smal1 budget changes in the first row. 
IV. The Effects on the Economy of Lowering the Deficit -- Table 4

Under most assumptions about monetary policy, the economy contracts when fiscal policy is tightened. A contraction in the economy increases the government deficit. Therefore, if the deficit is to be reduced by some amount, government spending will have to be cut by more than this amount. Estimates are presented in this section of the size of the spending cuts that are needed to meet a given deficit reduction.

Fiscal policy (2) was chosen for the present experiments. This is the case where the deficit is exogenous and government purchase of goods is endogenous. The same prediction period and the same perfect tracking solution were used here as were used for the results in Section III. For each experiment the deficit was reduced by 20 billion dollars. The results are presented in Table 4.

Consider first rows (a) and (b) in Table 4. Row (a) is for monetary policy (a) -- interest rate reaction function -- and row (b) is for monetary policy (b) -- exogenous money supply. In both cases the interest rate falls in response to the deficit reduction, but it does not fall nearly enough to prevent GNP from falling. The average decrease in nominal GNP for the first four quarters is 43.7 billion dollars in row (b) -- the average of 25.4 , $39.8,51.1$, and 58.6. The average decrease for real GNP is 18.7 billion (1972) dollars -- the average of $12.4,18.1,21.5$, and 22.6 . The average decrease in government purchases of goods for the first four quarters is 31.2 billion dollars -- the average of $26.6,30.4,33.4$, and 34.3 . The spending reduction was thus 11.2 billion dollars more than the deficit reduction in this case.

An interesting question to ask is how expansionary would monetary 
TABLE 4. Estimated Effects of a Sustained Lowering of the Deficit by 20 Billion Dollars

Fiscal Policy (2): Real government purchase of goods is endogenous

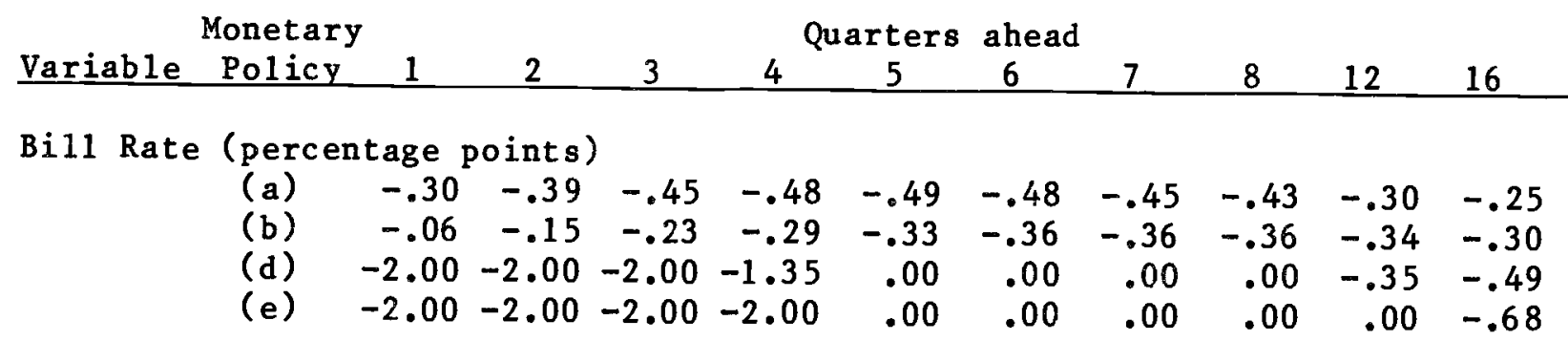

Money Supply (B\$)

$\begin{array}{lrrrrrrrrrr}\text { (a) } & .2 & .5 & .7 & .9 & 1.1 & 1.2 & 1.3 & 1.5 & 1.6 & 1.3 \\ \text { (b) } & 0 & 0 & 0 & 0 & 0 & 0 & 0 & 0 & 0 & 0 \\ \text { (d) } & 2.1 & 4.1 & 5.9 & 7.1 & 6.7 & 6.4 & 6.2 & 6.1 & 7.1 & 7.6 \\ \text { (e) } & 2.1 & 4.1 & 5.9 & 7.8 & 7.4 & 7.1 & 6.9 & 6.9 & 8.3 & 8.4\end{array}$

Nominal GNP (B\$)

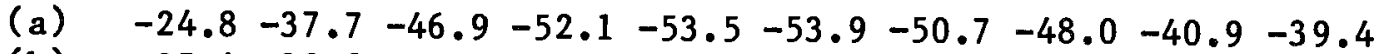

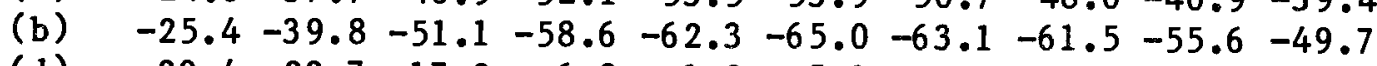

(d) $\quad \begin{array}{llllllllll}-20.4 & -22.7 & -17.2 & -6.9 & 1.2 & 5.1 & 5.0 & 2.7 & -3.4 & -4.3\end{array}$

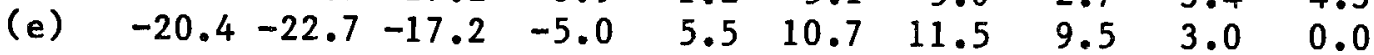

Real GNP (B72\$)

$\begin{array}{lrrrrrrrrrr}\text { (a) } & -12.1 & -17.0 & -19.5 & -19.8 & -19.1 & -17.3 & -14.9 & -12.8 & -5.7 & -4.6 \\ \text { (b) } & -12.4 & -18.1 & -21.5 & -22.6 & -22.8 & -21.7 & -19.6 & -17.7 & -9.6 & -5.7 \\ \text { (d) } & -9.6 & -9.5 & -5.5 & 0.0 & 3.4 & 4.7 & 4.4 & 2.8 & 0.0 & 0.0 \\ \text { (e) } & -9.6 & -9.5 & -5.5 & 1.0 & 5.4 & 7.1 & 7.0 & 5.3 & 2.1 & 0.8\end{array}$

GNP Deflator (percentage points)

$$
\begin{array}{lllllllllll}
\text { (a) } & -.06 & -.17 & -.28 & -.41 & -.49 & -.60 & -.65 & -.69 & -.83 & -.78 \\
\text { (b) } & -.06 & -.17 & -.29 & -.44 & -.53 & -.67 & -.72 & -.79 & -1.02 & -.99 \\
\text { (d) } & -.08 & -.15 & -.21 & -.23 & -.19 & -.15 & -.14 & -.10 & -.10 & -.11 \\
\text { (e) } & -.08 & -.15 & -.21 & -.23 & -.18 & -.13 & -.10 & -.05 & -.05 & -.05
\end{array}
$$

Gov. Purchase of Goods (B\$)

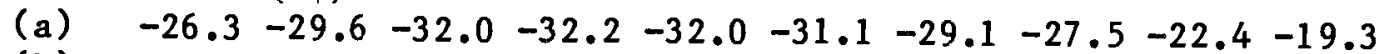

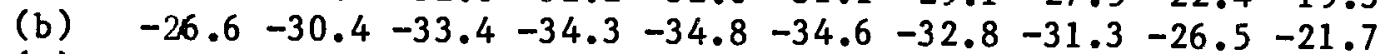

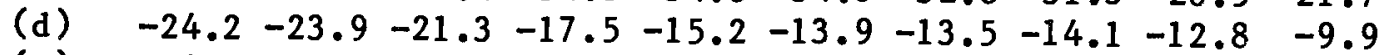

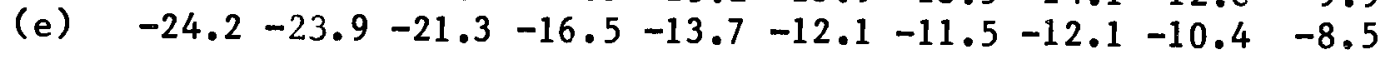

Notes: 1. See Table 1 for the units of the variables.

2. Monetary policy assumptions:

(a) = interest rate reaction function.

(b) = money supply is exogenous.

(d) = real GNP is exogenous unless the implied interest rate change is less than 2.0 or greater than 0.0 .

(e) = nominal GNP is exogenous unless the implied interest rate change is less than 2.0 or greater than 0.0 . 
policy have to be to have real or nominal GNP remain unchanged after the deficit reduction. It is possible in the model to take real GNP or nominal GNP as the target variable of the Fed. These cases are like case (b) except that it is real GNP or nominal GNP rather than the money supply that is the target. Case (d) will refer to targeting real GNP, and case (e) will refer to targeting nominal GNP.

There is a problem in implementing cases (d) and (e) in the present situation. Some of the main effects of interest rate changes on the other variables in the model occur with a lag, especially a lag of one quarter. This leads to the result that very large decreases in the interest rate are needed in the first quarter of a spending reduction to keep GNP unchanged. In the second quarter the lagged decrease in the interest rate (i.e., the decrease in the first quarter) is very stimulative, and in fact it is so stimulative that the change in the interest rate in the second quarter must be positive (relative to the base-path value) to keep GNP unchanged. In the third quarter the change is negative again; in the fourth quarter it is positive; and so on for a few more quarters. These large fluctuations in the interest rate are not likely to be a realistic description of Fed behavior, and so for the present results the interest rate changes have been "smoothed." The interest rate was never allowed to fall more than 2.0 percentage points below the base-path value in a quarter, and it was never allowed to rise above the base-path value. When either of these two constraints is binding in a given quarter, the change in real or nominal GNP will not be zero in that quarter. The change will be negative if the interest rate is prevented from falling and positive if the interest rate is prevented from rising. 
The results with the constraints imposed are presented in rows (d) and (e) in Table 4. Consider row (d) first, which pertains to real GNP targeting. In the first three quarters the negative constraint was binding and the interest rate fell 2.0 percentage points in each quarter. In the fourth quarter the constraints were not binding and the interest rate fell 1.35 points. The decreases in real GNP in the first three quarters were 9.6, 9.5, and 5.5 billion (1972) dollars. The change in the fourth quarter was zero since the constraints were not binding. In the next four quarters the positive constraint was binding, and the changes in the interest rate were zero. Real GNP increased in these quarters by $3.4,4.7,4.4$, and 2.8 billion (1972) dollars. The main result here is thus that a fall in the interest rate of about 2.0 percentage points in the first year and zero in the second year keeps real GNP over the two-year period abuout the same. Note that the fall in government purchases of goods is much smaller in row (d) than it is in rows (a) and (b). There are two main reasons for this. This first is simply that the economy is less contractionary in row (d), which means that tax revenues fall less, which means that a smaller spending reduction is needed to meet the deficit target. The second reason is that interest payments of the government are considerably less in row (d) because of the much lower interest rates. The larger the decrease in interest payments, the smaller need be the decrease in purchases of goods to meet the deficit target. This interest-payment effect is getting more important over time as the size of the government debt increases.

The results for nominal GNP targeting in row (e) are similar to those in row (d). To keep nominal rather than real GNP unchanged, the interest rate must fall somewhat more since nominal GNP also decreases because of the 
fall in prices. The fall in the interest rate must offset the decrease in nominal GNP due both to a fall in real output and a fall in the price level. In the present results the negative interest rate constraint was binding for the first four quarters rather than only the first three.

\section{Conclusions and Quatifications}

The main results of this paper have been summarized in Section $I$. The response of the economy to demand shocks is considerably greater when there is deficit targeting. This is not true of price shocks, since the deficit is not affected very much by price shocks. Under standard assumptions about monetary policy, a policy of reducing the deficit is contractionary, and the reduction in government spending must be greater than the targeted reduction in the deficit to achieve the target. A deficit reduction of 20 billion dollars can be accomplished with only a small decrease in GNP (over two years) by a decrease in the interest rate of about 2.0 percentage points in the first year. This is a much stronger monetary policy action than is implied by a policy of money-supply targeting or the policy that is reflected in the estimated interest rate reaction function.

The present results are subject to a number of qualifications. First, the experiments are not a true representation of the Gramm-Rudman bill because of timing differences. Under Gramm-Rudman, decisions are made once a year, whereas in the experiments the decisions are in effect made quarterly. These timing differences, however, do not affect the main points of the paper. For example, the response to a demand shock will still be larger under Gramm-Rudman because the government will eventually have to contract. 
Second, deficit reductions may be made with a combination of tax increases and spending reductions, and combinations were not considered in this paper. Enough results were presented, however, to give one a fairly good idea of what the effects of the combinations would be.

Third, the bill has certain recession stops in it, which were not considered here. If a recession is predicted, the automatic cuts are postponed. (As an interesting aside, it is clearly possible for no recession to be predicted without the cuts but for one to be predicted with the cuts. Joseph Heller should be pleased.)

Fourth, because the model is nonlinear, estimated effects differ across sample periods. The period used is this paper is 1981 I - 1985 III. If another period were used, the numbers in the tables would differ somewhat. Two types of nonlinearities are particularly important in the model. The first concerns the labor constraint variable and how close the economy is to full employment. Multiplier reactions are larger when the economy is far from full employment than when it is near. The second nonlinearity concerns the interest payments of the federal government. As noted earlier, the interest payment response is getting larger over time because of the growing size of the government debt.

Fifth, some may think that my model is no good. The model does not assume that expectations are rational, for example, which some think is the best approximation of the way that expectations are formed. Also, the model suffers from the Lucas (1976) critique. I have been concerned for quite a few years with the question of how one tests alternative models, and I have put my model through a number of tests. So far the model has held up we11.4 ${ }^{4}$ See, for example, Chapter 8 in Fair (1984). 
Also, I have recently tested more sophisticated expectational hypotheses than are used in the regular version of my model (Fair, 1985), and the results were not very supportative of the hypotheses. Finally, I have argued in Fair (1984) that the Lucas critique is likely to be of small quantitative importance but that if it is not, models that suffer from the critique should not do well in the tests that I have used. If the Lucas critique were quantitively important in my model, the model should not have done as well as it has in the tests.

Sixth, some may argue that whether the mode1 is good or bad is on $1 \mathrm{y}$ of historical interest because the structure of the economy in the future will be considerably different under Gramm-Rudman than it has been in the past. It has been argued, for example, that when the idea of Gramm-Rudman begins to sink in, the bond market will respond much differently than it has in the past (eg. long term interest rates will fall rapidly in anticipation of the lowering of the deficit). The animal spirits of firms may also change, and plant and equipment investment may boom. Similarly, the stock market may boom. If any of this is true, a number of the equations in the model are misspecified regarding the future behavior of the economy. One can never rule out changes in structure, which is one of the reasons there is so much difference of opinion in macroeconomics, but in my view the burden of proof is on those arguing for the changes.

Finally, the experiments do not consider possible international repercussions from the effects on the U.S. economy, which would modify the quantitative results at least slightly. This will be the subject of another paper. 
REFERENCES

Fair, Ray C., Specification, Estimation, and Analysis of Macroeconometric Models, Harvard University Press, 1984.

Fair, Ray C., "The Use of Expected Future Variables in Macroeconometric Mode1s," mimeo, revised May 1985.

Lucas, Robert E., Jr., "Econometric Policy Evaluation: A Critique," in K. Brunner and A. H. Meltzer, eds., The Phillips Curve and Labor Markets, North-Holland, 1976. 